\title{
Proses Pengolahan Air Pada Tangki Klarifier ditinjau dari Laju Alir dan Konsentrasi Koagulan di PLTG Borang
}

\author{
Anhar $^{* 1}$, Erwana Dewi ${ }^{2}$, Indah Purnamasari ${ }^{3}$ \\ 1,2,3Program Studi Teknologi Kimia Industri, Jurusan Teknik Kimia \\ Politeknik Negeri Sriwijaya, Indonesia. \\ Email : ${ }^{1}$ anhar.an223@gmail.com
}

\begin{abstract}
Abstrak
Kebutuhan industri akan air bersih sangatlah tinggi sehingga diperlukan proses pengolahan. PLTG Borang merupakan salah satu industri yang mendapatkan air bersih dengan melakukan pengolahan pada unit Water Treatment Plant. Unit WTP di PLTG Borang mengalami permasalahan di beberapa alat seperti misalnya pada clarifier tank. Tangki ini merupakan tempat terjadinya pengolahan air secara koagulasi dan flokulasi serta diikuti sedimentasi. Data-data yang dijadikan sumber yaitu data variabel proses dan hasil kualitas mutu air setelah pengolahan pada tangki clarifier. Data variabel proses yang diperlukan yaitu laju alir, kecepatan pengadukan dan dosis koagulan yang ditambahkan. Sedangkan kriteria kualitas yang diperlukan yaitu pH, turbiditas, TDS, dan TSS. Variabel proses divariasikan yaitu dosis koagulan sebesar 35, 40, 45, 50, dan 55 ppm; laju alir 2, 4 dan 6 L/detik serta kecepatan pengadukan $45 \mathrm{rpm}$. Analisis data yang dilakukan yaitu dengan menginterpretasikan data hasil pengamatan dan menyajikannya dalam bentuk grafik kemudian akan diperoleh kesimpulan. Variabel proses yang optimal adalah laju alir 2 L/detik, dosis koagulan 50 ppm dan kecepatan pengadukan 45 rpm. Hasil kualitas air setelah pengolahan di clarifier tank yaitu pH 7,2; Turbiditas 96 NTU; TDS 481 ppm; dan TSS 192 ppm.
\end{abstract}

Kata kunci: flokulasi, koagulasi, pengolahan air, tangki klarifier.

\section{Water Treatment Process in the Clarifier Tank in Terms of the Flow Rate and Coagulant Concentration in PLTG Borang}

\begin{abstract}
The industrial need for clean water is very high, so processing is needed. PLTG Borang is one of the industries that get clean water by processing it at the Water Treatment Plant unit. The WTP unit at the Borang PLTG experienced problems with several tools, such as the clarifier tank. This tank is a place for water treatment by coagulation and flocculation and followed by sedimentation. The data used as the source is the data of process variables and the results of water quality after processing in the clarifier tank. Process variable data needed are flow rate, stirring speed and dose of coagulant added. While the required quality criteria are pH, turbidity, TDS, and TSS. The process variables were varied, namely the coagulant dose of 35, 40, 45, 50, and 55 ppm; flow rates of 2, 4 and $6 \mathrm{~L} / \mathrm{sec}$ and stirring speed of $45 \mathrm{rpm}$. Data analysis is carried out by interpreting the observed data and presenting it in the form of graphs and then conclusions will be obtained. The optimal process variables are flow rate of $2 \mathrm{~L} / \mathrm{second}$, coagulant dose of $50 \mathrm{ppm}$ and stirring speed of $45 \mathrm{rpm}$. The results of water quality after processing in the clarifier tank are pH 7.2; Turbidity 96 NTU; TDS 481 ppm; and TSS 192 ppm.
\end{abstract}

Keywords: clarifier tank, coagulation, flocculation, water treatment

\section{PENDAHULUAN}

Clarifier tank merupakan tangki yang berfungsi untuk memisahkan flok yang terbentuk pada proses koagulasi dan flokulasi. Tangki klarifier ini dapat dirancang berbentuk segi empat, persegi panjang maupun silinder [1]. Alat ini digunakan untuk menjernihkan air baku yang keruh dengan cara melakukan pengendapan, untuk mempercepat pengendapan lazimnya ditambahkan koagulan dan flokulan agar terjadi proses koagulasi dan flokulasi pada air [2].

Pada unit Clarifier terjadi pengadukan lambat. Jenis pengadukan lambat pada Clarifier adalah jenis pengadukan hidrolis memanfaatkan piringan berlubang. Fungsi dari piringan berlubang yaitu untukmemecah 
aliran dalam menciptakan efek pengadukan. Pada proses pengadukan lambat, energi hidrolik yang dibutuhkan cukup kecil agar menghasilkan gerakan air yang mendorong kontak antar partikel tanpa menyebabkan terpisahnya gabungan flok yang telah terbentuk. Penggabungan inti gumpalan sangat tergantung pada gradien kecepatan [3].

Ada beberapa macam tangki klarifier yang sering digunakan. Berdasarkan bentuk dan sistem kerjanya tangki klarifier dapat diklasifikasikan menjadi 3 yaitu : inclined plate (lamella), rectangular, dan circular clarifier [4].

Proses yang terjadi pada clarifier tank yaitu : koagulasi, flokulasi dan sedimentasi. Proses koagulasi berarti proses pembubuhan bahan kimia (koagulan) untuk mendestabilisasikan partikel-partikel yang tersuspensi di dalam air baku agar terbentuk gumpalan yang lebih besar. Bentuk alat pengaduk cepat dapat bervariasi seperti rapid mixer, hidrolis (hydraulic jump) dan mekanis (menggunakan batang pengaduk). Bahan kimia dan konsentrasinya yang digunakan dalam proses pengadukan dari koagulan merupakan faktor penting dalam proses koagulasi [5].

Tujuan dari koagulasi adalah menggumpalkan partikel-partikel kecil sehingga berkumpul menjadi lebih besar dan bisa mengendap. Hal ini karena adanya proses pencampuran koagulan ke dalam air baku sehingga partikel ringan bersatu membentuk partikel berat [6].

Proses pembentukan flok akan berjalan dengan baik jika pembubuhan koagulan sesuai dengan dosis yang dibutuhkan. Flokulasi merupakan proses penggabungan antar partikel sehingga menjadi partikel-partikel yang lebih besar (flok) sehingga lebih mudah mengendap secara gravitasi. Bahan kimia yang dipakai, derajat keasaman serta waktu pengadukan merupakan faktor penentu yang mempengaruhi proses berlangsungnya flokulasi [5].

Proses sedimentasi merupakan proses setelah proses koagulasi-flokulasi yang berfungsi untuk memisahkan solid dan liquid dari suspensi untuk menghasilkan air yang lebih jernih melalui pengendapan secara gravitasi. Sedimentasi berfungsi sebagai peringan beban kerja unit filter dan memperpanjang lamanya kerja filter.

Bangunan pengolahan air sangat penting perananya dalam upaya memenuhi kualitas air bersih melalui pengolahan kimia, fisik, dan mikrobiologi [7]. Beberapa fasilitas yang dimiliki dalam proses pengolahan air bersih pada unit water treatment plant diantaranya adalah intake, bak pengendapan awal, clarifier, koagulator, filter, dan reservoir.

Kondisi intake sangat berpengaruh dalam suplai air yang akan diolah. Untuk menjamin suplai air cukup, intake diletakkan di lokasi yang mudah dicapai dan direncanakan untuk mensuplai jumlah kuantitas air pada kualitas optimal yang memungkinkan [8]. Kemudian proses prasedimentasi. Proses ini terjadi pada bak pengendapan awal. Air dari unit intake dialirkan menuju bak prasedimentasi untuk membuang pasir, lempung, jenis partikel non koloid lainnya secara gravitasi.

Partikel besar telah mengendap pada bak prasedimentasi. Setelah itu partikel kecil diolah pada alat clarifier tank. Partikel-partikel kecil digumpalkan sehingga membentuk flok yang lebih besar. Namun masih terdapat partikel seperti dissolved solid sehingga perlu diolah lagi pada bagian filtrasi.

Filtrasi dapat digunakan dengan menggunakan beberapa jenis filter, antara lain: saringan pasir lambat, saringan pasir cepat, bahkan dengan menggunakan teknologi membran. Pada pengolahan air bersih umumnya dipergunakan saringan pasir cepat, karena filter jenis ini memiliki debit pengolahan yang cukup besar, penggunaan lahan yang tidak terlalu besar, biaya operasi dan pemeliharaan yang cukup rendah dan tentunya kemudahan dalam pengoperasian dan pemeliharaan [9].

Air bersih yaitu air yang aman (sehat) dan baik untuk diminum, tidak berwarna, tidak berbau, dengan rasa yang segar [10]. Ketersediaan air bersih merupakan hal yang penting bagi suati industri [11].Air bersih di PLTG Borang digunakan untuk keperluan pencucian peralatan, domestik kantor dan pengisi hidran.

Permasalahan utama yang perlu diselesaikan yaitu menentukan dosis koagulan dan laju alir yang optimum pada clarifier tank agar didapat kualitas air bersih sesuai standar.

\section{METODE PENELITIAN}

\subsection{Waktu dan Tempat}

Studi Kasus Alat Clarifier Tank pada Unit Water Treatment Plant di PT PLN (Persero) PLTG Borang dilaksanakan pada bulan Maret - Juli 2021. Pengamatan dan Pengambilan data dilakukan di unit WTP bagian Clarifier Tank PLTG Borang pada April - Mei 2021. Adapun tahapan pelaksanaan studi kasus meliputi kegiatan lapangan, analisis data dan pelaporan.

\subsection{Prosedur Studi Kasus}


Studi kasus dimulai dengan mengumpulkan seluruh referensi berupa studi literatur sesuai dengan permasalahan. Perlakuan ditentukan berupa variabel proses terhadap kualitas air hasil pengolahan. Percobaan dilakukan terhadap alat dan mengumpulkan data pengamatan. Data pengamatan dilakukan analisis untuk

mendapatkan simpulan berupa variabel proses yang optimal agar mendapatkan kualitas air setelah pengolahan yang terbaik.

\subsection{Sumber Data}

Sumber data diambil dari data historisis, observasi langsung dan studi pustaka. Dalam hal ini data yang digunakan adalah data hasil pengamatan, data penelitian yang telah dilakukan oleh industri dan literatur atau pustaka yang mendukung studi kasus ini.

\subsection{Variabel Proses dan Kualitas Air Hasil}

Variabel proses divariasikan yaitu laju alir 2, 4, dan 6 L/s; dan dosis koagulan 35, 40, 45, 50, dan 55 ppm. Koagulan yang digunakan yaitu poli aluminium klorida (PAC). Salah satu kelebihan PAC yaitu dapat digunakan pada rentang $\mathrm{pH}$ yang besar [12]. Kualitas air yang akan diukur yaitu $\mathrm{pH}$, turbiditas, jumlah padatan terlarut, dan total padatan tersuspensi.

\subsection{Metode Analisis Data}

Analisis yang digunakan pada studi kasus ini yaitu analisis deskriptif dan interpretasi. Analisis deskritif yakni menghubung-hubungkan antara data yang satu dengan data yang lainnya, kemudian menarik benang merah dari data tersebut sehingga diperoleh gambaran secara utuh studi kasus yang dilakukan secara mendalam. Sedangkan analisis interpretasi yaitu dengan menyajikan data variabel proses dan hasil kualitas air ke dalam bentuk diagram atau grafik, kemudian menentukan hubungan serta kondisi optimum yang dicapai.

\section{HASIL DAN PEMBAHASAN}

Ada 4 kriteria kualitas air hasil proses yang dianalisis yaitu $\mathrm{pH}$, kekeruhan, jumlah padatan terlarut dan jumlah padatan tersuspensi. Derajat keasaman atau $\mathrm{pH}$ memiliki rentang standar $7-9$, sedangkan kekeruhan, TDS dan TSS memiliki nilai standar maksimum. Hal ini berarti kriteria baku mutu air setelah melewati alat clarifier tank yang meliputi kekeruhan, TDS dan TSS diharapkan mengalami penurunan, sedangkan pH harus berada pada rentang nilai standar.

\subsection{Pengaruh laju alir dan konsentrasi koagulan terhadap pH}

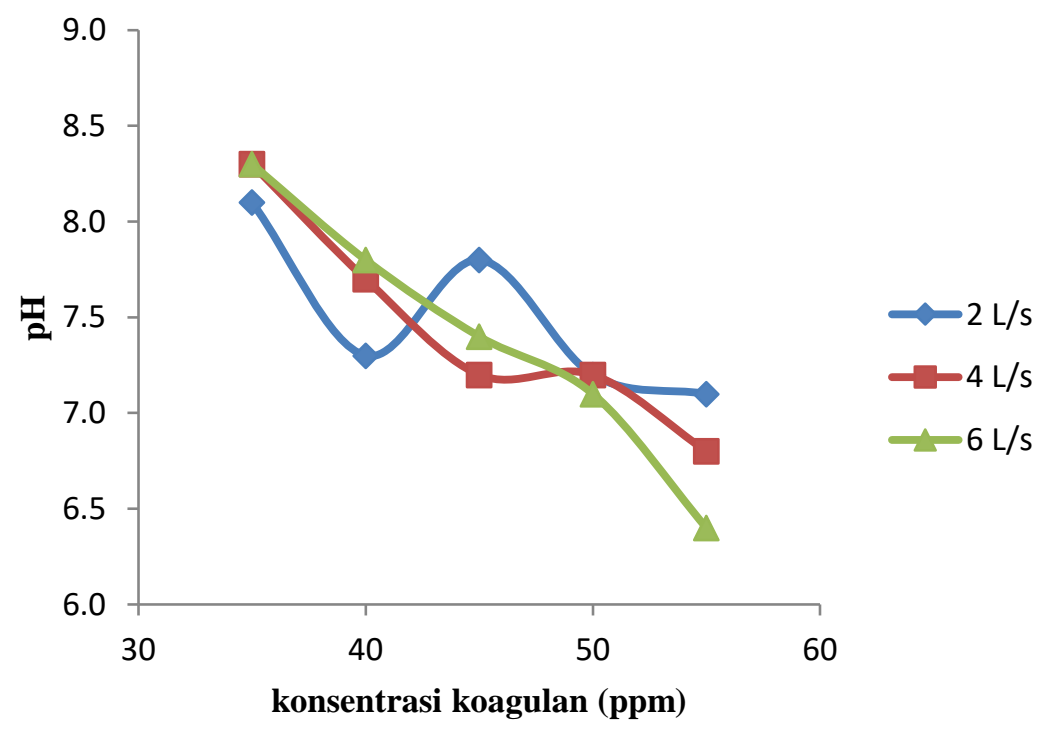

Gambar 1. Grafik pengaruh laju alir dan konsentrasi koagulan terhadap pH 
$\mathrm{pH}$ merupakan indikator untuk mengetahui tingkat keasaman ataupun basa dari suatu larutan. $\mathrm{pH}$ sangat besar pengaruhnya terhadap proses pengolahan air karena jika pengolahan air tidak terjadi pada $\mathrm{pH}$ optimum akan menyebabkan kualitas air yang dihasilkan rendah. Dimana perubahan $\mathrm{pH}$ pada air dapat menyebabkan perubahan pada bau, rasa maupun warna dari air tersebut. Grafik memiliki kecenderungan semakin tinggi

konsentrasi koagulan maka $\mathrm{pH}$ semakin rendah. Hal ini karena semakin besar dosis koagulan dalam suatu larutan, maka semakin besar juga kandungan ion $\mathrm{H}^{+}$dalam larutan tersebut akibat adanya proses hidrolisis. Namun jika dosis koagulan terlalu tinggi, maka $\mathrm{pH}$ akan menjadi asam dikarenakan koagulan PAC yang digunakan bersifat asam.

\subsection{Pengaruh laju alir dan konsentrasi koagulan terhadap turbiditas}

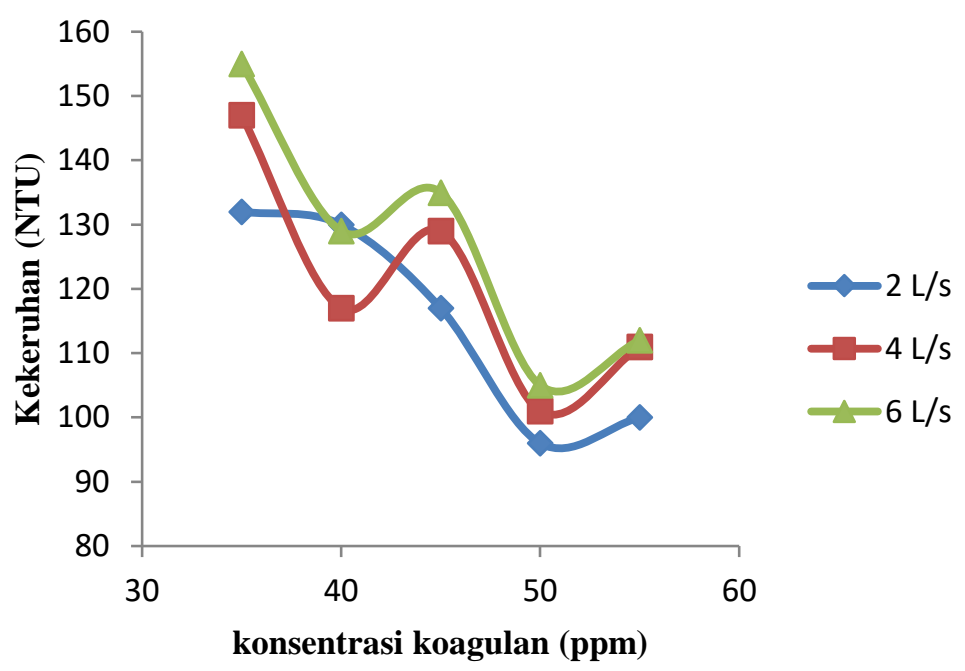

Gambar 2. Grafik pengaruh laju alir dan konsentrasi koagulan terhadap turbiditas

Makin besar laju alir maka makin rendah tingkat kejernihan air hasil olahan yang diperoleh. Hal ini terjadi karena pada laju alir yang besar kemungkinan lolosnya flok ke zona jernih akan semakin besar pula dan sebaliknya. Penggunaan koagulan yang semakin banyak akan menghasilkan turbiditas yang rendah sehingga air akan menjadi lebih jernih. Namun jika konsentrasi koagulan terlalu tinggi, maka akan mengurangi penurunan turbiditas. Hal ini disebabkan karena terjadi gaya tolak menolak diantara partikel yang bermuatan positif sehingga terjadi proses deflokulasi.

\subsection{Pengaruh laju alir dan konsentrasi koagulan terhadap TDS}

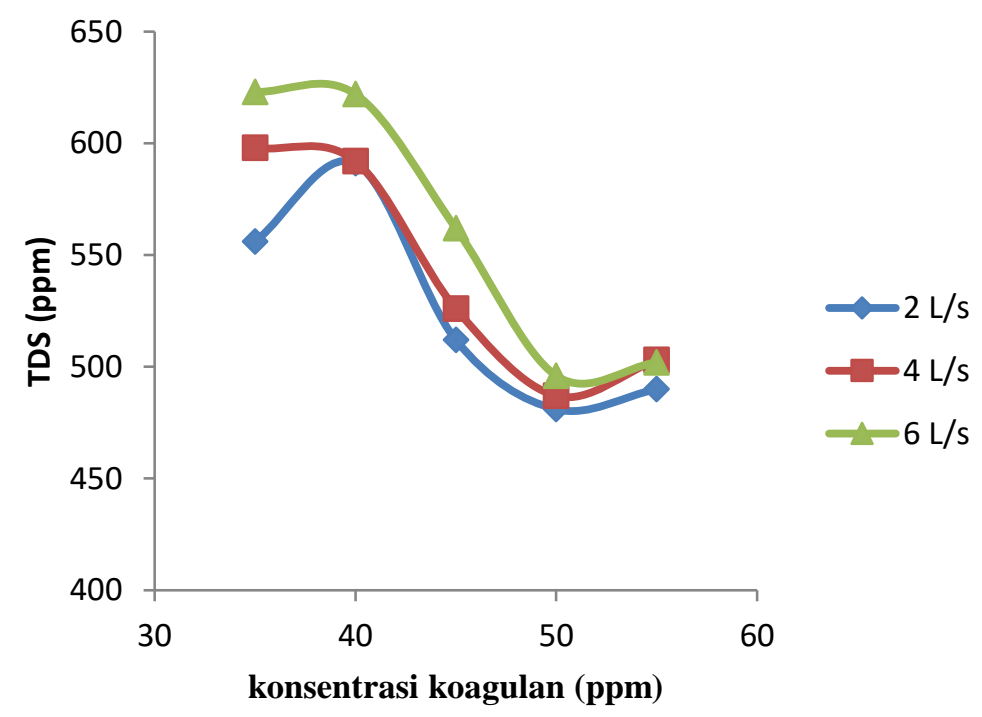

Gambar 3. Grafik pengaruh laju alir dan konsentrasi koagulan terhadap TDS 
Grafik memiliki kecenderungan makin besar laju alir maka makin besar pula jumlah padatan terlarut dalam air hasil olahan yang diperoleh. Hal ini terjadi karena pada laju alir yang besar kemungkinan lolosnya flok ke zona jernih akan semakin besar pula dan sebaliknya. Penggunaan koagulan yang semakin banyak akan menghasilkan TDS yang rendah sehingga air akan menjadi lebih jernih. Hal ini karena kemampuan koagulan

yang dapat mengikat zat-zat padat. Namun jika konsentrasi koagulan terlalu tinggi, maka akan mengurangi penurunan TDS. Hal ini disebabkan karena terjadi gaya tolak menolak diantara partikel yang bermuatan positif sehingga terjadi proses deflokulasi.

\subsection{Pengaruh laju alir dan konsentrasi koagulan terhadap TSS}

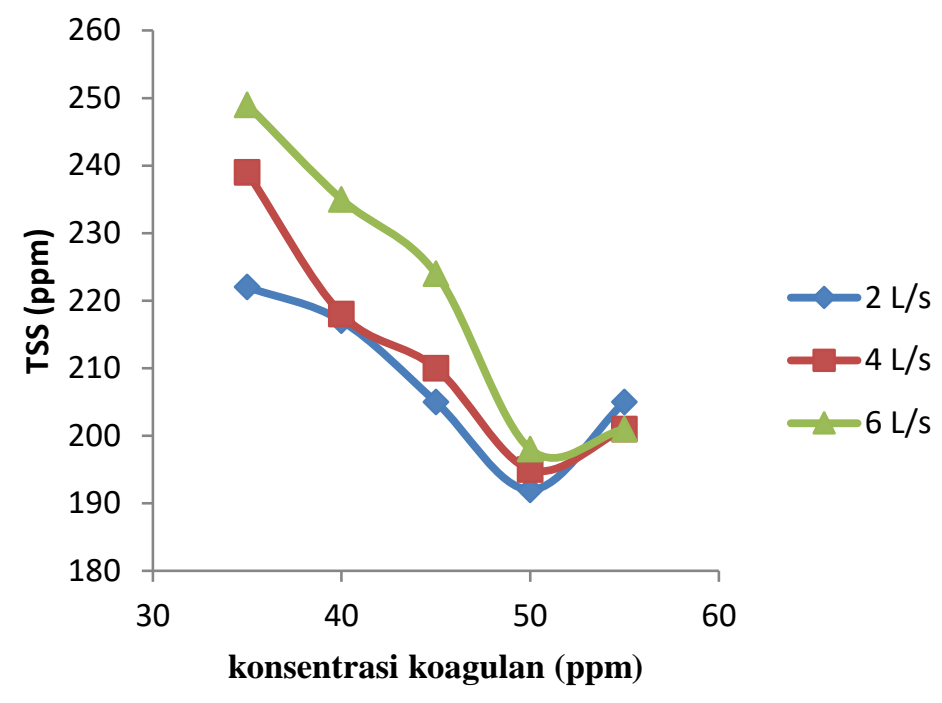

Gambar 4. Grafik pengaruh laju alir dan konsentrasi koagulan terhadap TSS

Laju alir semakin besar cenderung makin besar pula jumlah padatan tersuspensi dalam air hasil olahan yang diperoleh. Hal ini terjadi karena pada laju alir yang besar kemungkinan lolosnya flok ke zona jernih akan semakin besar pula. Penggunaan koagulan yang semakin banyak akan menghasilkan TSS yang rendah. Hal ini karena banyaknya koagulan yang dapat mengikat zat-zat padat tersuspensi. Namun jika konsentrasi koagulan terlalu tinggi, maka akan mengurangi penurunan TSS.

\section{KESIMPULAN}

Kesimpulan yang didapat adalah variabel proses yang optimum dari alat clarifier tank dalam mengolah air baku yaitu : konsentrasi koagulan PAC 50 ppm dan laju alir 2 L/detik. Selain itu hasil kualitas air adalah : pH 7,2; Turbiditas 96 NTU; TDS 481 ppm; dan TSS 192 ppm.

\section{DAFTAR PUSTAKA}

[1] Sumada, Tangki Klarifier. Bandung: Institut Teknologi Bandung, 2012.

[2] Puspita, Pengertian dan Sistem Kerja Tangki Clarifier. Bandung: Institut Teknologi Bandung, 2014.

[3] R. Anjar, "Evaluasi Efisiensi Kinerja Unit Clearator di Instalasi PDAM Ngagel I Surabaya," ITS, Surabaya, 2015.

[4] Feriyanto, "Pengolahan Air Proses Koagulasi dan Flokulasi", 2017. [Online]. Available: https://www.caesarvery.com/2017/07/koagulasikoagulanflokulasiflokulan.html.

[5] T. Kembara, "Optimalisasi Instalasi Pengolahan Air PDAM Tirta Daroy Kota Banda Aceh terhadap Tingkat Kekeruhan Air Saat Musim Penghujan," UIN Ar Raniry, Banda Aceh, 2018.

[6] Prakash, "Waste Water Treatment by Coagulation and Flocculation," International Journal of Engineering Science and Innovative Technology, vol. 3, no. 2, pp. 479-480, 2014.

[7] H. Gustinawati, "Evaluasi dan Optimalisasi Sistem Pengolahan Air Minum Pada IPA Jaluko Kapasitas 50 L/s Kabupaten Muaro Jambi," Jurnal Daur Lingkungan, vol. 1, no. 1, pp. 29-30, 2018. 
[8] H. A. Sobari, "Evaluasi Proses Pengolahan Air Bersih pada IPA PDAM Tirtana di Medan Sunggal," Universitas Sumatera Utara, Medan, 2020.

[9] R. A. D. Nugroho, "Analisa Perubahan Kualitas Air Baku dengan Menggunakan Model Koagulasi Flokulasi Sedimentasi dan Filtrasi," Universitas Muhammadiyah Yogyakarta, Yogyakarta, 2016.

[10] M. O. Triono, "Akses Air Bersih pada Masyarakat Kota Surabaya," Jurnal Ekonomi Terapan, vol. 2, no. 3, pp. 93-94, 2018.

[11] E. Noor, Supriatin dan Istingan, "Peningkatan Kualitas Pengolahan Air Bersih dengan Perbaikan Proses Oksidasi," Journal of Environment Engineering \& Waste Management, vol. 2, no. 2, p. 91, 2017.

[12] Z. Maulana dan Fitriyah, "Teknologi Pengolahan Air Bersih Menggunakan Media PAC," Jurnalis, vol. 1, no. 1, pp. 62-63, 2018. 